\title{
PHYSICAL FITNESS OF GIRLS PRACTISING ACROBATIC AND TRAMPOLINE GYMNASTICS COMPARED TO THAT OF GIRLS PRACTISING OTHER SPORTS IN THE SUBCARPATHIAN PROVINCE TEAM
}

\author{
ANTONI SEREDYNSSKI, EWA POLAK \\ University of Rzeszow, Faculty of Physical Education, Department of Individual Sports \\ Mailing address: Antoni Seredyński, Faculty of Physical Education, \\ Department of Individual Sport, 3 Towarnickiego Street, 35-959 Rzeszów, \\ tel. +48 17 8721861, fax: +4817 8721861, e-mail: antekseredynski@op.pl
}

\begin{abstract}
Introduction. The aim of this study was to determine the level of overall physical fitness of girls from the Subcarpathian Province Team (SPT) who practise acrobatic and trampoline gymnastics and compare it to that of other members of the SPT. A comparative analysis of the subjects' physique was also performed. Material and methods. The study was conducted on 175 female subjects who were members of the SPT in the youth and juniors categories. They were divided into three groups: 19 trampoline gymnasts, 35 acrobatic gymnasts, and 121 athletes practising other disciplines (named the SPT group). Overall physical fitness was determined using the International Physical Fitness Test (IPFT). The Body Mass Index, Rohrer's index, and Ponderal index were calculated on the basis of anthropometric measurements. The obtained data were analysed statistically. In order to determine the statistical significance of differences in the results for each group, ANOVA variation analysis and Tukey's HSD test were carried out. Results and conclusions. The athletes practising acrobatic and trampoline gymnastics had lower body height, lower body mass, and a slimmer physique than the girls from the SPT who performed other sports. However, it is not possible to clearly determine whether these differences were the result of practising a particular sports discipline. Compared to the SPT athletes practising other sports, the acrobats presented a higher level of overall fitness (apart from grip strength). This was evidenced by the higher scores they achieved for the IPFT (total number of points), trunk flexibility, shoulder muscle strength, and abdominal muscle strength. The fitness level of the trampoline gymnasts was similar to that of the SPT athletes who practised other sports (with better scores for trunk flexibility and lower ones for grip strength). The fitness profiles of the acrobatic and trampoline gymnasts were similar, and the group of acrobats achieved significantly higher scores only in trunk flexibility.
\end{abstract}

Key words: International Physical Fitness Test, adolescent, sport, acrobatic gymnastics, trampoline gymnastics

\section{Introduction}

Acrobatic and trampoline gymnastics are sports governed by the International Federation of Gymnastics (FIG). The essence of these sports is mastering the human body, and demonstrating that one can perform precise, aesthetic, confident, and extensive movements during exercises with a very complex structure. Both types of gymnastics have their specific features. Acrobatic gymnastics includes exercises of a static or dynamic character which are performed with a partner in pairs (women's, men's, or mixed) or in groups (women's trios or men's fours) to music on the gym floor [1]. In trampoline gymnastics the athletes perform individual exercises of a dynamic nature: multiple somersaults and twists. However, in both disciplines, as well as in other gymnastic sports (artistic gymnastics, rhythmic gymnastics, tumbling, and aerobic gymnastics), the common denominator is the perfect execution of exercises with a high degree of difficulty. To meet this requirement, gymnasts must have an optimal physique and high level of physical fitness.

The level of physical fitness, physique, their interaction, and the way they are impacted by environmental factors are of interest to researchers. Research studies pertaining to these issues are conducted in persons of different gender and age (school children, students, adults, or the elderly), living in various environments (rural areas, urban areas, or particular regions), and belonging to different social or occupational groups (practising particular sports and professions). Some examples would be the research concerning Polish youth that has been conducted by Przewęda and Dobosz [2, 3, 4] every 10 years in schools all over the country since 1979 and local studies carried out in Poland [5, 6, 7, 8, 9]. Many studies have also examined groups of athletes, including acrobats and trampolinists $[10,11,12,13,14,15,16]$. The level of overall physical fitness in children and adolescents who begin practising sports is particularly important. Its high level determines young people's opportunities to succeed in various sports and is a prerequisite for being eligible to practise sports professionally. Due to the specific nature of different sports, particular motor abilities can play a greater or lesser role; sometimes they are of fundamental importance and they determine the feasibility of specific motor tasks. This is particularly relevant in the case of gymnastic 
sports. It is not possible to perform an acrobatic or trampoline exercise without a certain level of flexibility, strength, balance (both static and dynamic), agility, coordination, and spatial orientation. An optimal level of these abilities, which determines special fitness, is achieved through systematic training, but the basis for achieving it is overall physical fitness. Its diagnosis and systematic control is crucial for the recruitment and selection of candidates for a particular sports discipline. It is also important in controlling their progress at various stages of their training.

The aim of this study was to determine the level of overall physical fitness of girls from the Subcarpathian Province Team (SPT) who practise acrobatic and trampoline gymnastics and compare it to that of other girls in the SPT. A comparative analysis of the subjects' physique was also carried out. In this study, the following research questions were formulated:

1. Are there significant differences in the physique of the acrobatic and trampoline gymnasts compared to that of the other members of the Subcarpathian Province Team?

2. Does the level of overall physical fitness of the acrobatic and trampoline gymnasts differ from the physical fitness of the comparison group?

3. Are the physical fitness profiles of the acrobatic and trampoline gymnasts similar to each other?

\section{Material and methods}

The study was carried out in 2013 on 175 female subjects who were members of the SPT in the youth and junior categories. The subjects were divided into three groups: 19 trampoline gymnasts (mean age $=11.3 \pm 2.54$ years), 35 acrobatic gymnasts (mean age $=12.9 \pm 2.57$ years), and 121 athletes from the SPT practising other sport disciplines (mean age $=13.7 \pm 2.36$ years). The SPT group consisted of girls who practised canoeing, kiokushin karate, road cycling, athletics, archery, alpine skiing, orienteering, volleyball, swimming, diving, shooting, chess, fencing, tennis, table tennis, and freestyle wrestling.

Overall physical fitness was determined using the International Physical Fitness Test (IPFT) [17]. In Poland, in accordance with the guidelines of the Polish Ministry of Sport and Tourism, the scores in this test are one of the main criteria used to appoint members of regional teams in various sports and approve them. IPFT scores are used to monitor progress in the training of athletes and are included in the annual reports prepared for the Competitive Sports Department. The study was conducted by the staff and students of the Faculty of Physical Education at the University of Rzeszów in cooperation with the Subcarpathian Sports Federation. Anthropometric measurements were performed, according to generally accepted methods developed by Martin and presented by Malinowski and Bożiłow [18]. Body mass and body composition were assessed using a TANITA TBF 300 scale. The Body Mass Index, Rohrer's index, and Ponderal index were calculated.

The obtained data were analysed statistically by calculating the following descriptive statistics: mean value $(\bar{\chi})$, standard deviation (SD), minimum (min), maximum (max), coefficient of variation (CV), and the index of normalised differences. The results were analysed using the Statistica 10 PL software package. In order to determine the statistical significance of the differences in the results obtained for each group, ANOVA variation analysis and Tukey's HSD test were conducted.

\section{Results}

On the basis of the ANOVA analysis, it was found that both study groups of gymnasts (the trampolinists and acrobats) were characterised by significantly lower body height, lower body mass, and lower BMI in relation to the comparison group, that is the members of the SPT practising other sports disciplines (tab. 1). The significance of these differences was also confirmed by Tukey's test, which simultaneously indicated there were no significant differences in these features between the trampoline and acrobatic gymnasts. The values of Rohrer's index and the Ponderal index of these two groups showed statistically significant differences, but this relationship was so small that Tukey's test did not confirm it.

Comparing the physique of the analysed groups of girls to the physique of their peers from the population of Polish youth and children from Rzeszów (tab. 2), it should be noted that the acrobats had lower body height, lower body mass, and lower BMI. Compared to girls from Rzeszów (aged 11) and girls from the Polish youth population (aged 11.5), the group of trampoline gymnasts was characterised by similar values for these features.

Table 1. Somatic features and indices of the groups studied

\begin{tabular}{|c|c|c|c|c|c|c|c|c|c|c|}
\hline Feature / index & Group & $\mathbf{N}$ & $\bar{\chi}$ & SD & $\min$ & $\max$ & CV [\%] & p & \multicolumn{2}{|c|}{ Dependence between groups } \\
\hline \multirow{3}{*}{ Body Height } & Trampoline & 19 & 146.8 & 16.99 & 122.5 & 175.0 & 11.57 & \multirow{3}{*}{$0.000 * *$} & T.SPT & $* * *$ \\
\hline & Acrobatic & 35 & 150.9 & 12.87 & 118.5 & 173.5 & 8.53 & & A-SPT & $* * *$ \\
\hline & SPT & 121 & 161.1 & 9.70 & 124.5 & 183.0 & 6.02 & & $\mathrm{~T}-\mathrm{A}$ & \\
\hline \multirow{3}{*}{ Body Mass } & Trampoline & 19 & 38.2 & 12.54 & 22.9 & 62.8 & 32.82 & \multirow{3}{*}{$0.000 * *$} & T-SPT & $* * *$ \\
\hline & Acrobatic & 35 & 41.2 & 13.15 & 18.8 & 66.0 & 31.95 & & A-SPT & $* * *$ \\
\hline & SPT & 121 & 52.3 & 11.04 & 22.8 & 90.5 & 21.11 & & T-A & \\
\hline \multirow{3}{*}{ BMI } & Trampoline & 19 & 17.3 & 2.27 & 13.1 & 20.5 & 13.13 & \multirow{3}{*}{$0.000 * *$} & T-SPT & $*$ \\
\hline & Acrobatic & 35 & 17.6 & 2.95 & 13.4 & 25.1 & 16.73 & & A-SPT & $* *$ \\
\hline & SPT & 121 & 20.1 & 3.34 & 14.6 & 35.4 & 16.62 & & T-A & \\
\hline \multirow{3}{*}{ RI } & Trampoline & 19 & 1.17 & 0.13 & 1.0 & 1.49 & 11.01 & \multirow{3}{*}{$0.016^{*}$} & T-SPT & \\
\hline & Acrobatic & 35 & 1.16 & 0.12 & 0.94 & 1.55 & 10.66 & & A-SPT & \\
\hline & SPT & 121 & 1.24 & 0.19 & 0.93 & 2.20 & 14.99 & & T-A & \\
\hline \multirow{3}{*}{$\mathrm{PI}$} & Trampoline & 19 & 44.11 & 1.57 & 40.6 & 46.49 & 3.56 & \multirow{3}{*}{$0.010^{*}$} & T-SPT & \\
\hline & Acrobatic & 35 & 44.30 & 1.52 & 40.1 & 47.32 & 3.43 & & A-SPT & \\
\hline & SPT & 121 & 43.37 & 1.80 & 35.8 & 47.48 & 4.16 & & $T \cdot A$ & \\
\hline
\end{tabular}

Level of statistical significance: ${ }^{*} \mathrm{p}<0.05,{ }^{*} \mathrm{p}<0.01,{ }^{* *} \mathrm{p}<0.001$; BMI - Body Mass Index, RI - Rohrer's Index, PI - Ponderal Index. 


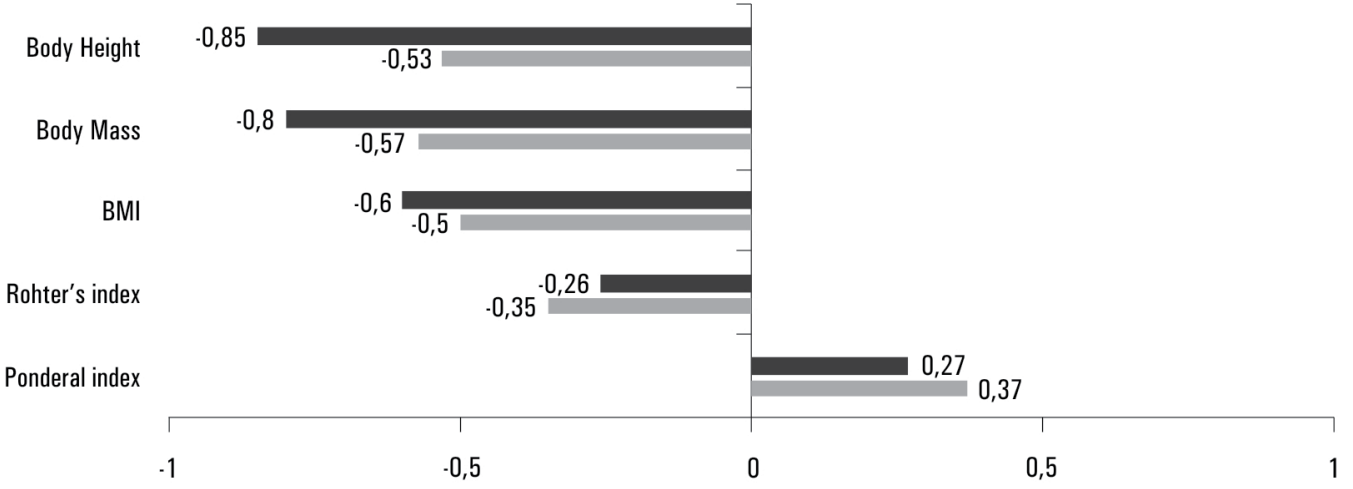

Figure 1. Normalised somatic features of the trampoline and acrobatic gymnasts, based on the arithmetic mean 0 and the standard deviation 1 from the comparison group (the SPT group)

Table 2. Somatic features of the groups studied compared to other groups

\begin{tabular}{|c|c|c|c|c|c|c|c|c|c|}
\hline \multirow{2}{*}{ Feature / Index } & \multirow{2}{*}{$\begin{array}{c}\text { Trampoline gymnasts } \\
\text { Aged } 11.3\end{array}$} & \multirow{2}{*}{$\begin{array}{l}\text { Acrobatic gymnasts } \\
\text { Aged } 12.9\end{array}$} & \multirow{2}{*}{$\begin{array}{l}\text { SPT group } \\
\text { Aged } 13.7\end{array}$} & \multicolumn{3}{|c|}{$\begin{array}{l}\text { Children from Rzeszów } \\
2008[7]\end{array}$} & \multicolumn{3}{|c|}{$\begin{array}{l}\text { Polish Youth Population } \\
1999 \text { [2] }\end{array}$} \\
\hline & & & & $\begin{array}{c}\text { Aged } \\
11\end{array}$ & $\begin{array}{c}\text { Aged } \\
12\end{array}$ & $\begin{array}{c}\text { Aged } \\
13\end{array}$ & $\begin{array}{l}\text { Aged } \\
11.5\end{array}$ & $\begin{array}{l}\text { Aged } \\
12.5\end{array}$ & $\begin{array}{l}\text { Aged } \\
13.5\end{array}$ \\
\hline Body Height [cm] & 146.8 & 150.9 & 161.1 & 146.1 & 153.3 & 158.1 & 149.3 & 155.8 & 160.0 \\
\hline Body Mass [kg] & 38.2 & 41.2 & 52.3 & 37.9 & 43.6 & 47.0 & 40.0 & 45.3 & 49.6 \\
\hline BMI & 17.3 & 17.6 & 20.1 & 17.6 & 18.4 & 18.7 & 17.9 & 18.7 & 19.4 \\
\hline $\mathrm{Rl}$ & 1.17 & 1.16 & 1.24 & 1.21 & 1.20 & 1.18 & $\cdot$ & $\cdot$ & $\cdot$ \\
\hline $\mathrm{PI}$ & 44.11 & 44.30 & 43.37 & $\cdot$ & $\cdot$ & $\cdot$ & 43.98 & 43.98 & 43.79 \\
\hline
\end{tabular}

BMI - Body Mass Index, RI - Rohrer's Index, PI - Ponderal Index.

Source: Own study based on previous research.

The examined SPT female athletes achieved better results in all fitness tests included in the IPFT than the population of Polish youth (tab. 3). This dependence became clear when we compared the level of physical fitness of the young athletes with that of their peers who did not practise sports. However, it was surprising that children from Rzeszów demonstrated better grip strength compared to the SPT athletes. In other tests the results of the SPT group were better than results of children from Rzeszów (tab. 3).

Table 3. IPFT results of the groups studied compared to other groups

\begin{tabular}{|c|c|c|c|c|c|}
\hline IPFT component & $\begin{array}{c}\text { Tram- } \\
\text { poline } \\
\text { gymna- } \\
\text { sts }\end{array}$ & $\begin{array}{c}\text { Acro- } \\
\text { batic } \\
\text { gymna- } \\
\text { sts }\end{array}$ & $\begin{array}{c}\text { SPT } \\
\text { group }\end{array}$ & $\begin{array}{c}\text { Children } \\
\text { from } \\
\text { Rzeszów } \\
\text { 2008 } \\
\text { (aged 13) } \\
\text { [7] }\end{array}$ & $\begin{array}{c}\text { Polish } \\
\text { Youth Po- } \\
\text { pulation } \\
\text { 1999 } \\
\text { (aged } \\
\text { 13.5) [2] }\end{array}$ \\
\hline 50 m run [s] & 9.2 & 8.8 & 8.6 & - & 8.9 \\
\hline Standing long jump [cm] & 157.8 & 171.1 & 171.7 & 152.6 & 161.3 \\
\hline $600 / 800$ m run [s] & 212.6 & 216.9 & 230.3 & - & 242.1 \\
\hline Hand dynamometry [kg] & 14.7 & 18.0 & 23.8 & 26.6 & 23.1 \\
\hline Bent arm hang [s] & 19.8 & 24.1 & 13.7 & - & 11.9 \\
\hline 4 x 10 m shuttle run [s] & 12.3 & 11.7 & 11.7 & - & 12.7 \\
\hline 30-second sit-ups [n] & 22.5 & 26.2 & 22.7 & 21.3 & 21.8 \\
\hline Standing forward bend & 13.1 & 21.1 & 8.8 & 7.1 & 6.7 \\
\hline [n] & & & & &
\end{tabular}

Source: Own study based on previous research.
In three tests included in the IPFT (30-second sit-ups, bent arm hang, and standing forward bend) the acrobats achieved significantly better results than the members of the SPT group. In three other tests (50 m run, standing long jump, and $4 \times 10$ $\mathrm{m}$ shuttle run) the average results of the acrobats and athletes practising other sports were similar or identical. On the other hand, the acrobats achieved poorer results in the $600 / 800 \mathrm{~m}$ run and hand grip strength test (tab. 3). The trampoline gymnasts had better results compared to the members of the SPT group in bent arm hang and standing forward bend (tab. 3). In the test of 30-second sit-ups the results of these two groups were similar. In all other fitness tests, the results of the trampoline gymnasts were poorer than those achieved by the members of the SPT group. These poor IPFT results could have been caused by the fact that the mean age of the trampoline gymnasts was more than two years lower than the mean age of the SPT group members. Therefore, it seemed more appropriate to compare the efficiency of all three groups of subjects (tab. 4) based on their IPFT score points calculated on the basis of the score tables of physical fitness for Polish youth [17].

In four tests which are part of the IPFT (50 m speed run, standing long jump, 600/800 m long run, and 4 x $10 \mathrm{~m}$ shuttle run) the scores of the athletes training acrobatics and trampoline gymnastics did not differ significantly from the scores of the athletes practising other sports who represented the SPT (tab. 4). In four other tests (hand dynamometry, bent arm hang, 30-second sit-ups, and standing forward bend) ANOVA showed statistically significant differences in the scores obtained by these three groups of athletes. In order to clarify which groups 
Table 4. IPFT scores of the groups studied

\begin{tabular}{|c|c|c|c|c|c|c|c|c|c|c|}
\hline IPFT component & Group & $\mathbf{N}$ & $\bar{\chi}$ & SD & $\min$ & $\max$ & CV [\%] & p & \multicolumn{2}{|c|}{ Dependence between groups } \\
\hline \multirow{3}{*}{50 m run } & Trampoline & 19 & 54.1 & 4.02 & 42.0 & 60.0 & 7.44 & \multirow{3}{*}{0.611} & T-SPT & \\
\hline & Acrobatic & 35 & 55.6 & 5.62 & 43.0 & 66.0 & 10.11 & & A-SPT & \\
\hline & SPT & 121 & 56.0 & 8.86 & 32.0 & 78.0 & 15.82 & & T-A & \\
\hline \multirow{3}{*}{ Standing long jump } & Trampoline & 19 & 54.2 & 7.17 & 41.0 & 67.0 & 13.23 & \multirow{3}{*}{0.433} & T-SPT & \\
\hline & Acrobatic & 35 & 56.7 & 6.72 & 44.0 & 70.0 & 11.86 & & A-SPT & \\
\hline & SPT & 121 & 54.4 & 10.04 & 23.0 & 88.0 & 18.46 & & T.A & \\
\hline \multirow{3}{*}{$600 / 800 \mathrm{~m}$ run } & Trampoline & 19 & 52.3 & 6.93 & 37.0 & 63.0 & 13.27 & \multirow{3}{*}{0.906} & T-SPT & \\
\hline & Acrobatic & 35 & 53.8 & 10.95 & 34.0 & 76.0 & 20.35 & & A-SPT & \\
\hline & SPT & 121 & 52.8 & 15.20 & 0.0 & 100.0 & 28.81 & & T-A & \\
\hline \multirow{3}{*}{ Hand dynamometry } & Trampoline & 19 & 41.6 & 10.58 & 28.0 & 64.0 & 25.41 & \multirow{3}{*}{$0.000 * *$} & T-SPT & * \\
\hline & Acrobatic & 35 & 41.9 & 11.46 & 23.0 & 68.0 & 27.33 & & A-SPT & $* *$ \\
\hline & SPT & 121 & 49.7 & 10.15 & 20.0 & 84.0 & 20.43 & & T-A & \\
\hline \multirow{3}{*}{ Bent arm hang } & Trampoline & 19 & 59.4 & 4.79 & 53.0 & 70.0 & 8.06 & \multirow{3}{*}{$0.000 * *$} & T-SPT & \\
\hline & Acrobatic & 35 & 61.2 & 7.08 & 49.0 & 77.0 & 11.57 & & A-SPT & $* *$ \\
\hline & SPT & 121 & 51.2 & 13.72 & 0.0 & 76.0 & 26.80 & & $\mathrm{~T} \cdot \mathrm{A}$ & \\
\hline \multirow{3}{*}{$4 \times 10$ m shuttle run } & Trampoline & 19 & 59.2 & 3.52 & 54.0 & 65.0 & 5.94 & \multirow{3}{*}{0.738} & T-SPT & \\
\hline & Acrobatic & 35 & 60.4 & 3.42 & 49.0 & 67.0 & 5.66 & & A-SPT & \\
\hline & SPT & 121 & 60.0 & 6.15 & 45.0 & 77.0 & 10.26 & & $\mathrm{~T} \cdot \mathrm{A}$ & \\
\hline \multirow{3}{*}{ 30-second sit-ups } & Trampoline & 19 & 54.1 & 8.71 & 40.0 & 74.0 & 16.11 & \multirow{3}{*}{$0.000 * *$} & T-SPT & \\
\hline & Acrobatic & 35 & 59.7 & 6.98 & 47.0 & 75.0 & 11.69 & & A-SPT & $* * *$ \\
\hline & SPT & 121 & 51.6 & 8.73 & 14.0 & 69.0 & 16.91 & & T-A & \\
\hline \multirow{3}{*}{ Standing forward bend } & Trampoline & 19 & 62.8 & 9.19 & 47.0 & 77.0 & 14.64 & \multirow{3}{*}{$0.000 * *$} & T-SPT & *** \\
\hline & Acrobatic & 35 & 75.8 & 9.99 & 61.0 & 97.0 & 13.17 & & A-SPT & $* *$ \\
\hline & SPT & 121 & 51.7 & 11.66 & 23.0 & 97.0 & 22.54 & & T-A & *** \\
\hline \multirow{3}{*}{ Total score } & Trampoline & 19 & 437.5 & 34.69 & 383.0 & 505.0 & 7.93 & \multirow{3}{*}{$0.000 * *$} & T-SPT & \\
\hline & Acrobatic & 35 & 457.1 & 50.57 & 226.0 & 540.0 & 11.06 & & A-SPT & $* *$ \\
\hline & SPT & 121 & 419.8 & 50.07 & 225.0 & 531.0 & 11.93 & & T-A & \\
\hline
\end{tabular}

Level of statistical significance: ${ }^{*} p<0.05,{ }^{* *} p<0.01,{ }^{* * *} p<0.001$.

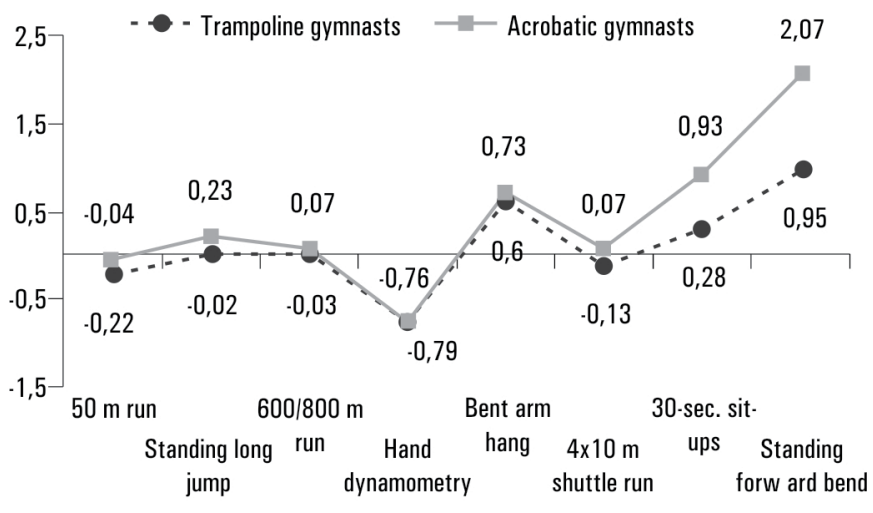

Figure 2. Physical fitness profiles of the trampoline and acrobatic gymnasts: normalised IPFT total score based on the arithmetic mean 0 and the standard deviation 1 from the comparison group (the SPT group)

of athletes differed significantly, Tukey's test was performed. It was found that both the acrobats and trampoline gymnasts achieved lower scores in the grip strength test than the SPT group (tab. 4). In the tests of bent arm hang and 30-second situps the scores of the acrobats were significantly better than those of the other SPT athletes. The largest difference in scores was observed in the standing forward bend test, in which both the acrobats and trampoline gymnasts achieved better scores than the SPT group. At the same time, the acrobats achieved significantly better scores in this test than the trampoline gymnasts (tab. 3). In the total scores for the IPFT, the group of acrobats achieved significantly better results than the SPT group.

The physical fitness profiles of the acrobatic and trampoline gymnasts are shown in figure 2 . These profiles were similar in the first six tests which are part of the IPFT. Both groups achieved similar scores in the $50 \mathrm{~m}$ speed run, standing long jump, 600/800 m run, and $4 \times 10 \mathrm{~m}$ shuttle run. These results were close to the ones achieved by the girls practising other sports (the SPT group). The scores in the tests of hand dynamometry and bent arm hang achieved by the acrobatic and trampoline gymnasts were also similar. However, in the test of grip strength the score was lower than that of the SPT group, and in the upper limb and shoulder strength test it was higher. The acrobats achieved better scores than the trampoline gymnasts in 30-second sit-ups and standing forward bend, but the significance of the differences was confirmed only for standing forward bend (using Tukey's test). The scores of both groups of gymnasts analysed were also better than the results of the SPT group, but the scores in sit-ups were significantly better only for the acrobats.

Table 5 presents a comparison of the IPFT scores of the Great Poland Province Team [19] and the three groups examined in this study (the trampoline gymnasts, acrobats, and SPT group). The SPT girls achieved better scores than young athletes from the Great Poland Province in two tests (standing 
long jump and bent arm hang). In the next six tests their scores were lower than those of the Great Poland Province Team. In particular, a clear difference to the disadvantage of the SPT girls could be seen in the $50 \mathrm{~m}$ speed run. When comparing the groups of acrobats and trampoline gymnasts to the members of the Great Poland Province Team, it should be noted that the scores of these groups were much higher in the bent arm hang and standing forward bend tests and lower in the hand dynamometry test. The total scores achieved by the acrobatic and trampoline gymnasts were better than the scores of both the other SPT athletes and the athletes from the Great Poland Province (tab. 5).

Table 5. IPFT scores of the groups studied compared to those of the Great Poland Province Team

\begin{tabular}{|c|c|c|c|c|}
\hline IPFT component & $\begin{array}{c}\text { Trampoline } \\
\text { gymnasts }\end{array}$ & $\begin{array}{c}\text { Acrobatic } \\
\text { gymnasts }\end{array}$ & $\begin{array}{c}\text { SPT } \\
\text { group }\end{array}$ & $\begin{array}{c}\text { Great Poland } \\
\text { Province Team } \\
\text { 2009 [19] }\end{array}$ \\
\hline 50 m run & 54.1 & 55.6 & 56.0 & 50.8 \\
\hline Standing long jump & 54.2 & 56.7 & 54.4 & 52.7 \\
\hline 600/800 m run & 52.3 & 53.8 & 52.8 & 52.1 \\
\hline Hand dynamometry & 41.6 & 41.9 & 49.7 & 52.9 \\
\hline Bent arm hang & 59.4 & 61.2 & 51.2 & 47.0 \\
\hline 4 x 10 m shuttle run & 59.2 & 60.4 & 60.0 & 58.0 \\
\hline 30-second sit-ups & 54.1 & 59.7 & 51.6 & 55.4 \\
\hline Standing forward bend & 62.8 & 75.8 & 51.7 & 54.5 \\
\hline Total score & 437.5 & 457.1 & 419.8 & 425.8 \\
\hline
\end{tabular}

Source: Own study based on previous research.

\section{Discussion}

Comparing the physique of the trampoline and acrobatic gymnasts and that of the SPT group was difficult due to the difference in the mean age of these groups. This difference was particularly large in the case of the trampoline gymnasts, who were approximately 1.5 years younger than the acrobats and more than two years younger than the other SPT athletes. The significant differences in body height, body mass, and BMI (tab. 1) were probably a consequence of this age difference. The age between 10 and 14 is a period when the phase of puberty begins in girls. During this period, there is an intense increase in height and weight, and there are related changes in other somatic features. Sexual maturation, which causes several physiological and functional changes in the body, begins. It is worth emphasising that there is considerable individual variation in the level of maturation for children of this age [20, 21].

Polish nationwide studies [2] have shown that the average differences in height and weight in girls who are between 11.5 and 12.5 years old are $6.5 \mathrm{~cm}$ and $5.3 \mathrm{~kg}$, and for those between 12.5 and 13.5 years old they are $4.2 \mathrm{~cm}$ and $4.3 \mathrm{~kg}$ (tab. 2). In studies of children from Rzeszów [7], the differences were even greater and were as follows: $7.2 \mathrm{~cm}$ and $5.7 \mathrm{~kg}$ for girls aged 11-12 years and $4.8 \mathrm{~cm}$ and $3.4 \mathrm{~kg}$ for those aged 12-13 years. A similar trend was also observed in studies of children from Cracow [6] in which the differences in height and weight of girls aged 11-12 years were $7.3 \mathrm{~cm}$ and $5.8 \mathrm{~kg}$, and for those aged 12-13 years these differences were $5.9 \mathrm{~cm}$ and $4.0 \mathrm{~kg}$.

Based on these comparative data it can be concluded that the difference of $14.3 \mathrm{~cm}$ (tab. 2) between the body height of the trampoline gymnasts (11.3 years old) and that of the SPT group (13.7 years old) was somewhat greater than in the case of the cited peer groups $(11-13 \mathrm{~cm})$. The body mass difference between the trampoline group and SPT group (14 kg) was also greater than between the peers from the comparative groups (9-10 kg) (tab. 2). A similar trend could be observed when comparing the group of acrobats and the SPT group. The acrobatic gymnasts were about $11 \mathrm{~cm}$ shorter and $11 \mathrm{~kg}$ lighter than the SPT group. In the groups of Polish youth and children from Rzeszów the differences in body height and body mass were much smaller (about $5 \mathrm{~cm}$ and $4 \mathrm{~kg}$ ). Simultaneously, the acrobats were shorter and lighter than their peers from the other groups (tab. 2). Based on these data it can be assumed that the statistically significant differences between the body height and weight of the athletes from the SPT group and the acrobats and trampoline gymnasts were not exclusively the result of this age difference. These differences could have been influenced by other factors (for example, the processes of recruitment and selection or the impact of special sports training on the athletes' physique). However, it was not possible to determine whether the differences in body shape and size between the groups of athletes in this study were also the result of the specific nature of the sports discipline practised. Lower mean values of the BMI and Rohrer's index and the higher mean value of the Ponderal index in the groups of acrobats and trampolinists showed that the athletes in these groups were leaner than the athletes in the SPT group (tab. 1 and 2).

Due to the age differences between the analysed groups of girls, statistical analysis did not include the comparison of the absolute results of particular tests. These results are shown in this paper in order to provide data for comparative studies with groups of young athletes from other disciplines or other regions (tab. 3). The level of overall physical fitness was specified on the basis of point values. The total scores achieved in the IPFT by all study groups (tab. 4) proved an average level of physical fitness, which is indicated by a score between 320 and 480 points according to the standards of Pilicz's classification [22].

The number of points scored in several tests which are part of the IPFT significantly differentiated the groups studied. The group of acrobats achieved significantly better scores than the SPT group in three IPFT tests: bent arm hang, 30-second sit-ups, and standing forward bend (tab. 4). Considering the nature of acrobatic exercises (for example, different forms of hand stands and elements of flexibility), the finding that the acrobatic gymnasts were characterised by higher trunk flexibility, abdominal muscle strength, and upper limb and shoulder strength than athletes practising other sport disciplines can be easily explained. The high level of fitness in these tests is a prerequisite for the proper execution of acrobatic exercises. On this basis, it can be concluded that the specificity of the sport, the nature of the recruitment and selection processes, and the nature of the training had had an impact on the high level of these motor abilities in the acrobats. Their overall physical fitness, measured by the IPFT total score, was also significantly better than the fitness of the athletes from the SPT practising other sports (tab. 4). The hand dynamometry test was the only test in which the acrobats achieved significantly lower scores than the SPT group.

Similarly to the acrobats, the trampoline gymnasts were better than the SPT group in trunk flexibility and poorer in grip strength (tab. 4). However, there were no statistically significant differences between the group of trampolinists and the SPT group in other tests included in the IPFT and in the total scores. It may be surprising that no differences were found for the scores in lower limb explosive strength (measured using the standing long jump test) achieved by the groups of trampoline gymnasts and SPT athletes practising other disciplines. The essence of trampoline gymnastics is the execution of routines consisting of 10 elements (forward or backward somersaults and twists) while bouncing on the trampoline bed. One of the conditions for the proper execution of the routine is appropriate jump height. It also impacts the score for the time of 
flight, which is one of the components of the total score given during a competition, in addition to execution and difficulty scores. Therefore, a high score of the trampoline gymnasts in the fitness test measuring lower limb explosive strength, which determines the time of flight (and duration of the routine), would seem fully justified. This thesis is confirmed by studies carried out in a group of trampoline gymnasts aged 12-13 [16]. In a standing long jump test they achieved the result of $180 \mathrm{~cm}$. Their result was much better than the results of the trampoline gymnasts $(157.8 \mathrm{~cm})$, the girls from the SPT group $(171.7 \mathrm{~cm})$, and the groups of Polish youth $(161.3 \mathrm{~cm})$ and children from Rzeszów $(152.6 \mathrm{~cm})$. This observation may be useful for trampoline coaches from the Subcarpathian Province in planning athletes' training.

Analysing the scores of the acrobatic and trampoline gymnasts, and in particular the curve shown in figure 2, it can be concluded that the physical fitness profiles of acrobatic and trampoline gymnasts were similar to each other. The only component of the IPFT in which the subjects practising these sports differed significantly was the test of trunk flexibility (tab. 4), in which the acrobats achieved better scores. It should be noted that the scores for trunk flexibility achieved by the group of trampoline gymnasts were significantly better than those of the other athletes in the SPT. Therefore, the acrobatic and trampoline gymnasts were characterised by better trunk flexibility, shoulder strength, and abdominal muscle strength (without statistical significance in the trampoline group), and lower grip strength than the SPT athletes who practised other sports.

Continuing to perform research involving young athletes from Subcarpathia and other regions of Poland may help to further investigate the issues concerning the relationship between the somatic traits of athletes, their overall physical fitness level, and the specificity of the sport discipline practised which were discussed in this paper. Using other tests and methods may contribute to extending the scope of research and to determining whether the profile of the overall physical fitness of young athletes is dependent on the sport they practise.

\section{Conclusion}

The following conclusions may be drawn based on the results of this study:

1. The athletes practising acrobatic and trampoline gymnastics had lower body height, lower body mass, and a slimmer physique than the athletes from the STP group who practised other sports. However, it is not possible to clearly determine whether these differences were due to differences in the average age of the groups studied or, to some extent, were the result of practising a particular sports discipline.

2. Compared to the athletes from the SPT who practised other sports, the acrobats presented a higher level of overall fitness (apart from grip strength). This was evidenced by the higher scores they achieved in the IPFT (total points), trunk flexibility, shoulder muscle strength, and abdominal muscle strength. The fitness level of the trampoline gymnasts was similar to that of the group of athletes practising other sports (better trunk flexibility and lower grip strength).

3. The fitness profiles of the acrobatic and trampoline gymnasts were similar to each other. This was evidenced by the similar scores they achieved in nearly all tests included in the IPFT. The group of acrobats achieved significantly better scores only in trunk flexibility.

\section{Literature}

1. Seredyński A. (2008). Acrobatic gymnastics: a description of the discipline, a set of rules and principles of judging, and a classification of acrobatic exercises. Rzeszów: Uniwersytet Rzeszówski. [in Polish]

2. Przewęda R., Dobosz J. (2006). The physical fitness of Polish youth. Studia i Monografie 98. Warsaw: AWF Warszawa. [in Polish]

3. Przewęda R. (2009). Changes in the physical condition of Polish youth in recent decades. Studia Ecologiae et Bioethicae 7(1), 57-71. [in Polish]

4. Dobosz J. (2012). Physical condition of children and young people of school age: growth charts. Warsaw: AWF Warszawa. [in Polish]

5. Gołąb S., Chrzanowska M., Sobiecki J., Żarów R., Kościuk T., Brudecki J. et al. (2007). The child of Cracow 2000. Physical fitness and body posture of children and youth from the city of Cracow. Studia i Monografie 22, Cracow: AWF Kraków. [in Polish]

6. Chrzanowska M., Gołąb S., Żarów R., Sobiecki J., Brudecki J. (2002). The child of Cracow 2000. The level of biological development of children and youth of the city of Cracow. Studia i Monografie 19, Cracow: AWF Kraków. [in Polish]

7. Czarny W., Nowosad-Sergeant E., Drozd S., Czarnota B., Czaja R., Ostrowski P. (2008). The child of Rzeszów. Rzeszów: EuroPrint. [in Polish]

8. Jaworski J., Lyakh V., Wieczorek T. (2009). Genetic and environmental impact on the variability level of somatic and motor development in the course of ontogenetic development in families from the ostrowiecki region. Polish Journal of Sport and Tourism 16(2), 101-114.

9. Jurgielewicz-Urniaż M., Urniaż J. (2010). Somatic and motor development of junior high school students from Warmia and Mazury against the background of nationwide research. Polish Journal of Sport and Tourism 17(2), 128131.

10. Trzcińska D., Tabor P., Olszewska E. (2009). The level of somatic development and physical fitness of male volleyball players aged 15-16. In K. Górniak, M. Lichota (eds), Correction and compensation of physical development disorders in children and youth (pp. 283-294). Biała Podlaska: ZWWF.

11. Eider J. (1999). Body height and body weight of girls practising artistic gymnastics aged 7-15 years. Nowa Medycyna 7, 41-44. [in Polish]

12. Polak E. (2007). Acrobatics and trampoline gymnastics in Polish scientific research. Rozprawy Naukowe AWF we Wrocławiu 25, 30-34. [in Polish]

13. Szyszka D., Majewska M., Drozdowski S. (2007). Changes in the physical fitness of young female and male acrobats in ontogenesis. Annales Universitatis Mariae CurieSkłodowska. Sectio D. Medicina 62 (8 Suppl. 18), 227-231. [in Polish]

14. Celka R. (2003). Physical fitness and body build of highclass trampoline competitors Poznań. In W. Starosta, W. Osiński (eds), New Ideas in Sport Sciences: Current Issues and Perspectives. Part 1 (pp. 47-50). Leszno: Państwowa Wyższa Szkoła Zawodowa im. J. A. Komeńskiego w Lesznie.

15. Niźnikowska E., Niźnikowski T., Wiśniowski W., Bołoban W. (2005). The dynamism of coordination motor abilities of children practising acrobatics at a general training stage. In J. Sadowski (ed.), Coordination motor abilities in scientific research (pp. 448-453). Biała Podlaska: Józef Piłsudski Academy of Physical Education. 
16. Kamiński P., Kuba L., Świat T. (2009). Physical fitness of athletes practising trampoline gymnastics. Rozprawy Naukowe AWF we Wrocławiu 29, 522-527. [in Polish]

17. Pilicz S., Przewęda R., Dobosz J., Nowacka-Dobosz S. (2004). Physical fitness score tables of Polish youth. Criteria for measuring aerobic capacity using the Cooper test. Warsaw: AWF Warszawa. [in Polish]

18. Malinowski A., Bożiłow W. (1997). Basics of anthropometry. Methods, techniques, standards. Warsaw-Łódź: Wydawnictwo Naukowe PWN. [in Polish]

19. Karpowicz K., Strzelczyk R., Karpowicz M. (2012). The structure of the level of motor effects in young sportsmen at the stage of specific training. In R. Strzelczyk, K. Karpowicz (eds), Organising the sports training process in stages - theory and reality (pp. 87-100). Poznań: AWF Poznań. [in Polish]

20. Malinowski A. (2004). Auxology. Human development from a biomedical perspective. Zielona Góra: Uniwersytet Zielonogórski. [in Polish]

21. Shakhlina L.G., Socha T. (2010). Puberty phase in girls key questions in connection with sport mastery. Antropomotoryka 51, 97-107.

22. Ulatowski T. (2003). Comprehensive psychophysical efficiency. In T. Ulatowski (ed.), Selected texts regarding the theoretical basis of sport (pp. 147-161).Warsaw: Warszawsko-Mazowieckie Stowarzyszenie Związków Sportowych. [in Polish]

Submitted: January 9, 2015

Accepted: March 10, 2015 